\title{
ESTILOS DE APRENDIZAGEM VERSUS TREINAMENTO VIVENCIAL AO AR LIVRE
}

\author{
Individual learning styles versus Outdoor experiential training
}

\section{Carlos Eduardo Rodrigues Moreira ${ }^{1}$ Luciano Munck ${ }^{2}$}

\section{Resumo}

O objetivo deste estudo foi analisar a relação entre estilos individuais de aprendizagem e o treinamento vivencial ao ar livre. Os treinamentos vivenciais tiveram como técnicas o arvorismo, dinâmicas de grupo e paintball. Para alimentar a análise, foram aplicados dois instrumentos de pesquisa a cento e cinco participantes dos treinamentos: o Learning Style Inventory (LSI) e um questionário para identificação da satisfação. A coleta de dados foi realizada nos próprios locais de treinamento, sendo a identificação dos estilos de aprendizagem realizada antes, e a da satisfação, depois dos treinamentos. Os dados evidenciaram que o estilo de aprendizagem predominante entre os participantes da pesquisa foi o estilo acomodador (24,8\%). A satisfação foi predominantemente alta, com $100 \%$ das respostas variando entre mais ou menos satisfeito e muito satisfeito (arvorismo $\mathrm{P}=0,006$ ). Os dados da pesquisa demonstraram fraca influência dos estilos individuais de aprendizagem na maior ou menor satisfação para com os treinamentos recebidos. Em

1 Possui graduação em Administração de Empresas (2007) e especialização em Gestão Contemporânea de Recursos Humanos (2009) pela Universidade Estadual de Londrina (UEL), atualmente é mestrando em Administração (Gestão de Organizações) pelo Programa de Pós-Graduação em Administração, UEM/UEL. Desenvolve pesquisas nas áreas de aprendizagem, treinamento e desenvolvimento empresarial. E-mail: carlos@caputconsultoria.com.br

2 Possui graduação em Administração de Empresas pela Universidade Federal de Viçosa (1997), mestrado em Engenharia de Produção pela Universidade Federal de Santa Catarina (1999) e doutorado em Administração pela Universidade de São Paulo (2005). Atualmente é professor da Universidade Estadual de Londrina e Pontifícia Universidade Católica do Paraná. Tem experiência na área de Administração, com ênfase em Recursos Humanos, atuando principalmente nos seguintes temas: alinhamento estratégico, aprendizagem e gestão por competências. Atualmente coordena o mestrado em administração do Departamento de Administração da UEL. Desenvolve pesquisas na área de gestão por competências, aprendizagem e sustentabilidade, com publicações em períodicos e anais científicos como RAM, ReAD e ENANPAD. Desenvolve consultoria na área de gestão por competências. Email:munck@uel.br 
suma, concluiu-se que os treinamentos vivenciais ao ar livre possuem características que proporcionam alta satisfação para diferentes habilidades e estilos de aprendizagem. Informação essa que deveria ser levada em consideração por gestores e líderes no momento de planejar e estruturar programas de treinamento e desenvolvimento para seus colaboradores.

Palavras-chave: Estilos de aprendizagem; eficácia, treinamento; treinamento vivencial.

\begin{abstract}
The aim of this study was to analyze the relationship between individual learning styles and outdoor experiential training. The experiential training had techniques like, tree top walk, group dynamics and paintball. For the analysis, were applied two survey instruments to one hundred and five participants of the training: the LSI (Learning Style Inventory) and a self-applicable satisfaction questionnaire. Data collection was performed in training sessions with the Learning styles being collected before and satisfaction after the sessions. The results showed that the predominant learning style among the participants was de acomodative $(24,8 \%)$. Satisfaction was predominantly high, with 100\% of answers varying from more or less satisfied and very satisfied (tree top walk $P=0.006)$. The survey data showed weak influence of individual learning styles in more or less satisfaction in experiential training. In short, it was concluded that the outdoor experiential training have characteristics that provide high satisfaction for different abilities and learning styles. This information should be taken in considerations by managers and leaders when planning and structuring a training and developing programs for its employees.
\end{abstract}

Keywords: Learning styles, efficacy, training, live training.

\title{
Introdução
}

As constantes evoluções tecnológicas, o processo de globalização econômica e a abertura dos mercados internacionais provocaram mudanças significativas na economia, motivando uma intensificação da competição global e dando surgimento a novas estratégias empresariais e a novos padrões competitivos entre as organizações.

Este novo cenário imprimiu às empresas a necessidade de reduzir custos e melhorar, constantemente, a qualidade dos produtos e serviços oferecidos, pois, somente assim, as organizações poderão atuar e se desenvolver com êxito em mercados concorrenciais. Produtos e serviços de qualidade não são mais diferenciais, as empresas necessitam de diferenciais competitivos claros, ou seja, que agreguem valor aos seus produtos e/ou serviços e ofereçam benefícios que os concorrentes não possuem.

As empresas são, basicamente, sustentadas por conhecimentos, e sua correta aplicação, algo que apenas o ser humano é capaz de produzir, gerenciar e aplicar de forma contextualizada, portanto, torna-se cada vez mais imprescindível que as organizações invistam no aperfeiçoamento e na capacitação contínua do seu capital mais valioso, as pessoas. Para isso, um dos subprocessos de recursos humanos mais importantes e que vem sendo utilizado para subsidiar a construção de conhecimentos, é o treinamento e desenvolvimento (T\&D), modernamente também chamado de educação continuada.

Segundo uma pesquisa realizada pela Motorola University (2002), quando um participante assiste a uma palestra de forma passiva, o aproveitamento do conteúdo não passa de $5 \%$, ao passo que este pode chegar a $85 \%$ quando há participação ativa do treinando no processo.

Dentro desta proposta, a metodologia vivencial de treinamento vem se destacando. Essa modalidade sugere atividades em que os participantes são retirados de suas zonas de con- 
forto e estimulados a enfrentar desafios, vencer seus limites e transpor os problemas impostos. Caracterizado pela experimentação ativa dos treinandos, a modalidade vivencial proporciona o desenvolvimento de habilidades e competências comportamentais com um índice de aproveitamento muito superior às demais metodologias e, por este motivo, tem conquistado a cada ano a preferência das organizações.

Contudo, para definir qual a modalidade de treinamento é mais indicada e que deve ser adotada em cada caso, é preciso compreender que cada indivíduo possui características diferentes e distintas capacidades de abstração. Vários estudos sobre as teorias da aprendizagem têm demonstrado que os indivíduos possuem formas singulares de obter conhecimento, ou seja, as pessoas diferem-se umas das outras em inúmeros aspectos, portanto, não se pode tratar a aprendizagem como um processo vivenciado por todos da mesma maneira.

A partir do momento em que as empresas consideram as diferenças individuais de aprendizagem de seus colaboradores, barreiras cognitivas são superadas e os esforços de ensino e aprendizagem são otimizados. Deste modo, realizar um estudo sobre esta temática torna-se apropriado em função do movimento do mercado que busca e exige alternativas mais práticas e eficazes para capacitar as pessoas. Ou seja, desenvolver programas de treinamento em que os profissionais obtenham um aproveitamento maior, em um menor espaço de tempo e com um custo acessível.

Diante deste contexto e almejando contribuir para o aprimoramento do conhecimento a respeito da articulação dos temas mencionados acima, este estudo procurou investigar a relação entre os estilos individuais de aprendizagem e a satisfação com o treinamento vivencial ao ar livre a partir da avaliação da reação dos sujeitos (colaboradores de empresas clientes) que fizeram parte dos programas de treinamentos vivenciais ao ar livre, realizados no segundo semestre de 2008, por uma consultoria na área de treinamento e desenvolvimento empresarial da cidade de Londrina/PR.

\section{Treinamento e desenvolvimento de pessoas}

O capital humano passou a ser questão vital para o sucesso do negócio, o principal diferencial competitivo das organizações bem-sucedidas. As corporações necessitam de pessoas espertas, ágeis, inteligentes, empreendedoras e dispostas a assumir riscos. São as pessoas que fazem as coisas acontecerem, que conduzem os negócios, criam os produtos e prestam os serviços de maneira excepcional. E, para isso, as empresas investem pesadamente em programas de treinamento e desenvolvimento de pessoas. Para essas seletas empresas, treinamento não é um custo, pelo contrário, trata-se de um precioso e rentável investimento no futuro da organização e nas pessoas que nela trabalham.

O treinamento vem sendo utilizado com o objetivo geral de desenvolver pessoas, tanto na aprendizagem de novas habilidades quanto na ampliação daquelas já existentes, uma vez que as pressões socioculturais, tecnológicas, econômicas e políticas direcionam as organizações contemporâneas a se adaptarem às exigências que o mercado impõe, focando mais intensamente seu capital humano. De forma mais simples, pode-se dizer que treinamento significa levar alguém a ser capaz de fazer algo que ele nunca fez antes, e fazê-lo sem a assistência de quem ensina.

Embora, muitas vezes, os termos treinamento e desenvolvimento sejam nomeados indistintamente, eles possuem aspectos distintos. Ainda que seus métodos sejam similares para 
afetar a aprendizagem, as suas perspectivas de tempo são diferentes. Conforme Bohlander, Snell e Sherman (2003), o termo treinamento é utilizado para referenciar qualquer esforço que a empresa faça no sentido de estimular o aprendizado de seus colaboradores e mudar seu comportamento de maneira permanente. Segundo os autores, este termo estaria mais voltado às ações que objetivam resultados em curto prazo, e o termo desenvolvimento seria mais oportuno para identificar ações de ampliação das habilidades e competências dos colaboradores, preparando-os para assumir responsabilidades futuras. Ou seja, os termos treinamento e desenvolvimento, quando combinados, servem para definir todas as atividades que as empresas realizam com o objetivo de ampliar e desenvolver as habilidades, competências e conhecimentos que os funcionários necessitam para desempenhar de forma satisfatória suas atividades.

Existem quatro etapas fundamentais para a realização de um programa de treinamento eficaz e satisfatório, são eles: levantamento das necessidades específicas da empresa, planejamento do treinamento, execução e, por último, avaliação dos resultados alcançados pelo programa. Milkovich e Boudreau (2000, p.119) comentam que, após diagnosticar as necessidades de treinamento, o responsável pelo evento deverá, junto à empresa contratante, determinar o tema que será abordado, o perfil dos participantes, a data e o local de realização, a metodologia de aprendizagem que será adotada, o facilitador do treinamento e, por fim, os objetivos que a organização almeja atingir com a realização deste treinamento. Após obter informações a respeito de todos esses itens, pode-se considerar que o projeto do treinamento está bem estruturado e tem grandes chances de alcançar os objetivos propostos.

Após a execução propriamente dita do treinamento, a próxima etapa (avaliação) determina se os objetivos preestabelecidos no planejamento foram atingidos e avalia quais outros resultados o treinamento trouxe para a empresa.

\section{Avaliação e satisfação do treinamento}

Edwards Deming, considerado um dos maiores conhecedores sobre o assunto, dizia que "para obter qualidade é preciso treinar, treinar e continuar treinando". Contudo, hoje em dia não basta treinar; o treinamento precisa atingir resultados; precisa assegurar que o programa solicitado seja orientado de modo a satisfazer as necessidades específicas da organização (CAMPOS et al., 2004).

O treinamento, em alguns casos, tem um custo exageradamente elevado e pouco ou nenhum resultado palpável. Trata-se de programas nada eficazes, verdadeiras "perfumarias", que não acrescentam nada em termos de competências, conhecimentos ou habilidades. De acordo com Castro (1998), apenas 10\% do que é gasto pelas empresas em programas de treinamento são convertidos em informações ou habilidades que verdadeiramente se agregam à rotina de trabalho dos colaboradores.

A eficácia de um treinamento é o retorno, o resultado, que a empresa-cliente obtém sobre o investimento realizado. Já a satisfação se refere ao modo como as partes envolvidas interpretam e qualificam o programa em relação às suas expectativas individuais. A análise e mensuração da satisfação e da eficácia desses programas ficam a cargo dos processos denominados avaliação e validação do treinamento. Ulrich (2000, p.157) afirma que "não se pode gerenciar o que não se pode medir", ou seja, na busca por maximizar as habilidades e competências de seus profissionais, as empresas recorrem a investimentos na área de T\&D, transformando esses processos em ferramentas importantíssimas para a tomada de decisões estratégicas. 
Dentre os atuais modelos que avaliam e validam os programas de treinamento, o que mais se destaca é o proposto por Kirkpatrick (1977), que divide o processo de avaliação em quatro níveis: reações, comportamento, aprendizado e resultados. O critério de reações avalia a satisfação do treinando em relação ao programa, considera-se como satisfatório ou não e o quanto acredita ter aprendido com o treinamento. O critério de aprendizado analisa quanto conhecimento foi transferido aos participantes durante o treinamento. Já o critério do comportamento verifica se o aprendiz realmente está fazendo aquilo que Ihe foi ensinado durante o treinamento. E, por último, o critério dos resultados avalia se o programa teve ou não os resultados esperados. De acordo com a pesquisa "O Retrato do T\&D no Brasil 2006-2007", apresentada pela ABTD (2009), cerca de $40 \%$ das organizações utilizam as opiniões dos aprendizes e dos clientes internos como critérios para avaliar o impacto dos seus programas de T\&D.

No passado, as organizações e seus respectivos gestores encaravam os investimentos em T\&D como um custo. A questão básica que sempre surgia entre esses profissionais era se realmente valia a pena investir capital em um programa como esse. Hoje, mesmo sem instrumentos tão confiáveis e precisos, poucas questões parecem tão consensuais quanto à noção de que o treinamento e o desenvolvimento de pessoas são ferramentas cruciais para o crescimento e a sobrevivência das organizações. Sendo assim, pode-se afirmar que desenvolver ferramentas confiáveis para mensurar a eficácia dos programas de treinamento se configura como um dos grandes desafios para os profissionais dessa área.

\section{Estilos de aprendizagem}

De acordo com Kolb (1984), a aprendizagem é descrita como um processo em que conceitos e comportamentos são originados e constantemente modificados pela experiência. Ou seja, é a partir da experimentação que o indivíduo é capaz de gerar novos conceitos para nortear seus comportamentos, com o intuito de se tornar mais eficiente frente aos novos desafios ou diante de situações já vivenciadas.

O modelo de aprendizagem, proposto por Kolb (1984), tem sua ênfase atribuída à ação, denominando-se experiencial. A aprendizagem não depende de uma única função especializada como a cognição ou percepção. Envolve o funcionamento integrado do organismo como um todo, como o pensamento, sentimento, percepção e comportamento. Trata-se de um processo contínuo de transformação, criação e recriação de conhecimentos, e não um ente independente de aquisição e transmissão.

Para Kolb (1984), o processo de aprendizagem é composto de quatro etapas consecutivas, caracterizando um ciclo de aprendizagem. Esse ciclo se inicia quando o indivíduo se envolve em vivências concretas, nas quais realiza, passa para as observações e reflexões sobre seu contato com o mundo, elabora conceitos abstratos e generalizações que permitem um novo contato com a realidade e, por fim, testa os resultados e suas implicações em novas situações por meio da experimentação ativa, levando o indivíduo ao início do ciclo para novas vivências concretas e assim sucessivamente. Cada indivíduo hierarquiza essas etapas, conferindo maior destaque àquelas em que melhor se adapta e é capaz de absorver mais informações nesse estágio do que nos demais.

De acordo com o autor, a maioria das pessoas desenvolve estilos de aprendizagem que priorizam determinadas fases do ciclo em detrimento de outras. Isso acontece como resultado do equipamento hereditário, das exigências do ambiente onde este indivíduo está inserido e, principalmente, em virtude das experiências de vida de cada um. A ênfase que o aprendiz dá 
à maneira como processa a experiência vivida é o estilo de aprendizagem que irá desenvolver. Sendo assim, pode-se afirmar que o processo de aprendizagem não é idêntico para todos.

A partir de seu trabalho, Kolb (1984) encontrou quatro estilos de aprendizagem predominantes. O primeiro deles é o estilo Convergente, composto por pessoas que tomam decisões rápidas e apresentam habilidades na aplicação prática das ideias. Aprendizes com estas características não são nada sociais e se dão melhor em situações em que exista apenas uma resposta ou solução correta para o problema. O segundo estilo é o Divergente, que apresenta forças de aprendizagem totalmente contrárias às do convergente. Em geral, esses indivíduos são extremamente emotivos, relacionam-se muito bem, apresentam facilidade na geração de novas ideias e conseguem naturalmente associar a teoria com a prática. O estilo Assimilador utiliza-se da dedução para resolver problemas e se interessa mais pela lógica de uma ideia do que pelo seu valor prático. Possui grande capacidade para criar modelos teóricos, recolhendo ideias desencontradas e transformando-as em explicações coerentes. O último estilo de aprendizagem é o Acomodador, que utiliza a sua criatividade para mudar e fazer sempre o melhor. Indivíduos com este perfil possuem facilidade para desenvolver competência para realizar atividades e executar planos, além de serem líderes natos.

\section{Treinamento vivencial ao ar livre}

A sabedoria milenar ensina: "O que ouço, esqueço. O que vejo, lembro. O que faço, aprendo". O método vivencial trabalha exatamente estes três conceitos, fazendo com que a aprendizagem seja adicionada através de experiências didáticas, simulações e trabalhos lúdicos. Os participantes enfrentam situações que questionam seus paradigmas, exigindo criatividade e vontade de mudar para superá-las.

Trata-se de um método dinâmico que possibilita ao treinando um maior discernimento em relação ao processo decisório empresarial, uma vez que é composto por atividades que oportunizam vivenciar situações análogas ao cotidiano das organizações. Funciona como uma espécie de laboratório. Sendo assim, se pilotos utilizam simuladores de voo e biólogos realizam experimentos em laboratórios, executivos recorrem às técnicas vivenciais para testar e treinar estratégias e decisões e avaliar seus respectivos resultados.

Essa metodologia tem crescido a cada ano entre as organizações, pois facilita o desenvolvimento de habilidades e competências comportamentais, com um índice de aproveitamento muito superior às demais metodologias encontradas no mercado.

Como podemos observar no quadro 1 , todo treinamento é menos proveitoso quando seus participantes interagem de forma passiva. Neste ponto, a metodologia vivencial se difere, pois é caracterizada pela experimentação ativa dos participantes, em que o papel principal da aprendizagem fica a cargo do próprio treinando. Isso facilita um envolvimento maior deste, na busca por uma aprendizagem mais efetiva, proveitosa, competitiva e duradoura (SAUAIA, 1995).

Inúmeras atividades proporcionam aos participantes a oportunidade de aprender por meio da metodologia vivencial, dentre elas, destaca-se a técnica do outdoor training ou, simplesmente, treinamento ao ar livre. Para Zvingila (2002), outdoor training é todo treinamento que acontece fora do ambiente habitual de trabalho. Trata-se de uma técnica de aprendizagem na qual os participantes são submetidos a atividades que tem por base esportes de aventura e modalidades do ecoturismo. As atividades mais comuns para a prática do treinamento ao ar livre são: rafting, arvorismo, rapel, escalada, trekking, paintball, entre outros. 


\begin{tabular}{|l|l|}
\hline \multicolumn{1}{|c|}{ Tipo de Apresentação } & Percentual de Absorção \\
\hline Palestras & \\
\hline Leitura & $5 \%$ \\
\hline Recursos Áudio Visuais & $10 \%$ \\
\hline Demonstrações & $20 \%$ \\
\hline Discussões em Grupo & $30 \%$ \\
\hline Quando Pratica & $50 \%$ \\
\hline Quando Ensina & $75 \%$ \\
\hline
\end{tabular}

Quadro 1 - Índice de aproveitamento dos treinamentos.

Fonte: Motorola University (2002).

\section{Estilos de aprendizagem versus treinamento vivencial ao ar livre}

Frente a este cenário globalizado, em que as empresas exigem que seus colaboradores sejam cada vez mais dinâmicos e eficientes, é preciso rever a efetividade das atuais metodologias e propor novos procedimentos de aprendizagem, com o intuito de potencializar o índice de aproveitamento dos participantes nesses programas.

Dentro desta proposta, o treinamento vivencial ao ar livre vem se destacando e cresce a cada ano na preferência das organizações. Esta técnica proporciona ao treinando a oportunidade de aprender através do método da experimentação, ou seja, vivenciar na prática as competências, habilidades, atitudes e conceitos inerentes às suas atividades.

Nesta modalidade de treinamento, não há certo ou errado, bom ou ruim. Trata-se de uma oportunidade de se autoconhecer, construir insight, arriscar e experimentar mudanças. As pessoas são os próprios agentes da transformação, e aprendem fazendo e vivenciando todo o processo de aprendizagem. Quando se aprende algo novo de forma integrada, pode-se afirmar que o assunto passou a "fazer sentido", ou seja, significa que foi interiorizado. Assim, a retenção é maior quando o conteúdo é vivenciado, e não apenas teorizado.

A partir da teoria da aprendizagem experiencial proposta por David Kolb, conclui-se que cada indivíduo é único na forma como recebe e processa as informações, lida com as diferentes situações de aprendizagem e, efetivamente, aprende. Portanto, não se pode tratar a aprendizagem como um processo vivenciado por todos da mesma maneira. Cada aprendiz tem uma história diferente de vida, com experiências de aprendizado bem-sucedidas e outras nem tanto. Este conjunto de vivências serve como pano de fundo para a definição do estilo predominante de aprendizagem de cada indivíduo.

De acordo com Kolb (1997, p. 21), quando o professor conhece e respeita os estilos de aprendizagem dos seus alunos, proporcionando uma instrução em consonância com os mes- 
mos, verifica-se um aumento do aproveitamento acadêmico. Porém, quando o estilo de ensino é diferente do estilo de aprendizagem do aluno, este se torna desinteressado, desatento ou desagregador em classe. Além disso, apresenta baixo desempenho em seu processo de avaliação, desmotivando-se com a disciplina e com o curso em si.

Dentro do contexto organizacional, todos esses detalhes devem ser levados em conta na elaboração de um programa de treinamento. Para que o treinamento seja realmente eficaz e satisfatório, além de ser elaborado de forma personalizada, ou seja, de acordo com as necessidades e características específicas da organização, é primordial que o facilitador determine a metodologia de ensino e a técnica do treinamento levando em conta o perfil e o estilo de aprendizagem de cada participante.

Portanto, para que o treinamento ao ar livre (outdoor training) seja eficaz, é preciso, a exemplo das demais modalidades de aperfeiçoamento, conhecer previamente o perfil dos participantes e identificar os estilos de aprendizagem predominantes no grupo. Ter acesso antecipado ao perfil dos participantes é muito importante. Imagine que uma determinada empresa contrate um consultor para ministrar um treinamento vivencial ao ar livre para a sua equipe de vendas, mas não forneça nenhuma informação a respeito dos participantes do evento. O consultor desatento também não percebe este detalhe e elabora o programa a partir da técnica vivencial de arvorismo, esporte radical que demanda grande esforço físico e controle emocional. Somente no dia do evento o consultor tem o primeiro contato com os participantes e, espantado, percebe que todos são idosos e a maioria possui restrições físicas e motoras. Exemplos como este são mais comuns do que se imagina, portanto, é fundamental definir quem serão os participantes, quais são as suas reais condições físicas e se demandam algum cuidado especial.

O mesmo treinamento aplicado a grupos de pessoas com o mesmo perfil (idade, sexo, preparo físico etc.) pode apresentar diferentes resultados no que refere à satisfação e à retenção do conteúdo ministrado. Ou seja, mesmo com capacidades físicas semelhantes, algumas pessoas apresentam facilidades e dificuldades com determinadas técnicas de treinamento, reflexos do seu estilo de aprendizagem predominante. Portanto, também é fundamental definir antecipadamente ao treinamento os estilos de aprendizagem dos envolvidos, pois são fatores determinantes na avaliação da eficácia e satisfação do programa.

Considerando que o treinamento vivencial ao ar livre representa a opção de aperfeiçoamento pessoal com maior índice de aproveitamento por parte dos participantes, deseja-se, com este estudo, identificar qual dos quatro estilos de aprendizagem propostos por Kolb apresenta maior retenção de informações e satisfação com esse modelo de treinamento. Com este dado, conhecer-se-ia o grupo específico de indivíduos em que o treinamento vivencial ao ar livre proporciona um aprendizado mais eficaz e duradouro.

Deste modo, realizar um estudo sobre esta temática torna-se apropriado em função do movimento do mercado que busca alternativas para capacitar de forma mais otimizada os colaboradores e em um menor espaço de tempo. 


\section{Metodologia}

Com o objetivo de identificar as inter-relações entre os estilos de aprendizagem e a satisfação dos participantes com os treinamentos vivenciais ao ar livre, propõe-se uma pesquisa de campo definida como estudo de caso. As opções metodológicas definem esse estudo de caso com características de survey, o qual implica em coletar e quantificar dados de uma amostra, transformando-a em fontes confiáveis de informações (VERGARA, 2005).

De acordo com os parâmetros metodológicos, este estudo se caracteriza como uma pesquisa quantitativa. Já em relação aos objetivos o procedimento se classifica como do tipo descritivo, pois abrange uma pesquisa que coleta dados sobre duas ou mais variáveis nos mesmos sujeitos e determina as relações entre essas variáveis.

Participaram desta pesquisa 105 sujeitos, colaboradores de empresas clientes que fizeram parte dos programas de treinamento ao ar livre, realizados no segundo semestre de 2008, por uma empresa de consultoria na área de treinamento e desenvolvimento empresarial da cidade de Londrina, PR. A maioria dos participantes eram pessoas do sexo masculino, na faixa etária dos 30 aos 50 anos, a grande maioria com formação superior. A característica em comum mais relevante é que todos ocupavam cargos de liderança (gerentes, supervisores, diretores etc.) dentro das suas organizações. Os sujeitos da pesquisa foram avaliados em três técnicas vivenciais de treinamento ao ar livre: arvorismo, dinâmicas de grupo e paintball.

Durante esta pesquisa descritivo-quantitativa, foram utilizados dois instrumentos: um para avaliação dos estilos de aprendizagem e outro para avaliar a satisfação dos participantes com o treinamento vivencial:

- Inventário de estilos de aprendizagem: inventário desenvolvido por Kolb (1997), baseado em sua teoria dos estilos de aprendizagem, que avalia quatro habilidades dominantes: experiência concreta, observação reflexiva, conceituação abstrata e experimentação ativa. O questionário é composto por quatro colunas com nove adjetivos cada, que são referentes às características pessoais que discriminam as quatro habilidades dominantes. A interação entre as quatro habilidades possibilita a definição dos estilos de aprendizagem;

- Questionário de satisfação: o questionário de satisfação com o treinamento visa a avaliar a eficácia do treinamento vivencial ao ar livre a partir do conceito das reações proposto por Kirkpatrick (1993), que define a reação dos participantes como uma forma de avaliar a eficácia de um treinamento. Essa avaliação visa a determinar a satisfação dos participantes com o processo de treinamento, com o intuito de coletar opiniões honestas (anônimas) e focadas na percepção da qualidade da vivência do treinamento. O questionário foi composto por 34 questões referentes à satisfação com o treinamento, respondidas de forma anônima, através de uma escala likert de 6 pontos, categorizadas em ( $1=$ Muito insatisfeito; $2=$ Insatisfeito; $3=$ Mais ou menos insatisfeito; $4=$ Mais ou menos satisfeito; $5=$ Satisfeito; $6=$ Muito satisfeito). Este questionário foi desenvolvido pelos pesquisadores de acordo com o referencial teórico do estudo.

Os questionários foram aplicados nos dias e locais de treinamento estipulados pela consultoria. O Inventário de Estilos de Aprendizagem foi aplicado antes das sessões de treinamento, com o objetivo de identificar o estilo de aprendizagem adotado por cada sujeito da pesquisa. Após a sessão de treinamento, os sujeitos responderam ao questionário de satisfação.

A análise dos dados quantitativos foi feita através da estatística descritiva (média e percentual) para caracterização dos estilos de aprendizagem e dos níveis de satisfação dos sujeitos. A diferença entre os estilos de aprendizagem dos grupos de diferentes treinamentos 
vivenciais ao ar livre (paintball, arvorismo e dinâmicas de grupo), da satisfação entre os grupos dos diferentes treinamentos vivenciais e a relação entre a satisfação e os treinamentos vivenciais foram avaliadas através do teste qui-quadrado para tendências (3x2) (THOMAS; NELSON, 2002). O quadro 2 apresenta as variáveis do estudo.

\begin{tabular}{|l|l|l|}
\hline \multicolumn{1}{|c|}{ ESTILOS DE APRENDIZAGEM } & \multicolumn{1}{|c|}{$\begin{array}{c}\text { SATISFAÇÃO COM O } \\
\text { TREINAMENTO }\end{array}$} & \multicolumn{1}{|c|}{ TREINAMENTOS VIVENCIAIS } \\
\hline - Convergente; & - Muito satisfeito; & - Arvorismo; \\
- Divergente; & - Satisfeito; & - Paintball; \\
- Assimilador; & - Mais ou menos satisfeito; & - Dinâmicas de grupo. \\
- Acomodador. & - Mais ou menos insatisfeito; & \\
& - Insatisfeito; & \\
& - Muito Insatisfeito. & \\
\hline
\end{tabular}

Quadro 2 - Variáveis do estudo

O estudo limita-se pela escolha da sua amostra (conveniência); o mais indicado seria adotar uma amostra representativa para a população de trabalhadores da cidade de Londrina, localizada no estado do Paraná. Entretanto, a escolha do estudo de caso com uma determinada empresa de consultoria foi feita para ajustar o modelo da pesquisa aos objetivos delineados e ao tempo para realização da pesquisa.

\section{Apresentação e análise dos resultados}

Considerando as questões referentes à investigação da relação entre os estilos de aprendizagem e os treinamentos vivenciais ao ar livre, considerando os índices de satisfação, os resultados serão apresentados em tópicos. O primeiro tópico irá abordar os estilos de aprendizagem dos participantes dos treinamentos vivenciais. No segundo tópico, serão apresentados os níveis de satisfação com os treinamentos vivenciais ao ar livre e o terceiro tópico apresentará a relação entre os estilos de aprendizagem e a satisfação com o treinamento vivencial ao ar livre.

\section{Estilos de aprendizagem}

O processo de aprendizagem é, segundo Kolb (1978), um processo contínuo de criação de conhecimento através da transformação da experiência. A partir das suas pesquisas, o autor identificou quatro estilos de aprendizagem predominantes: o convergente, o divergente, o assimilador e o acomodador. O gráfico 1 apresenta a frequência (percentual) dos estilos de 
aprendizagem diagnosticada nos participantes dos treinamentos vivenciais utilizados nesta pesquisa.

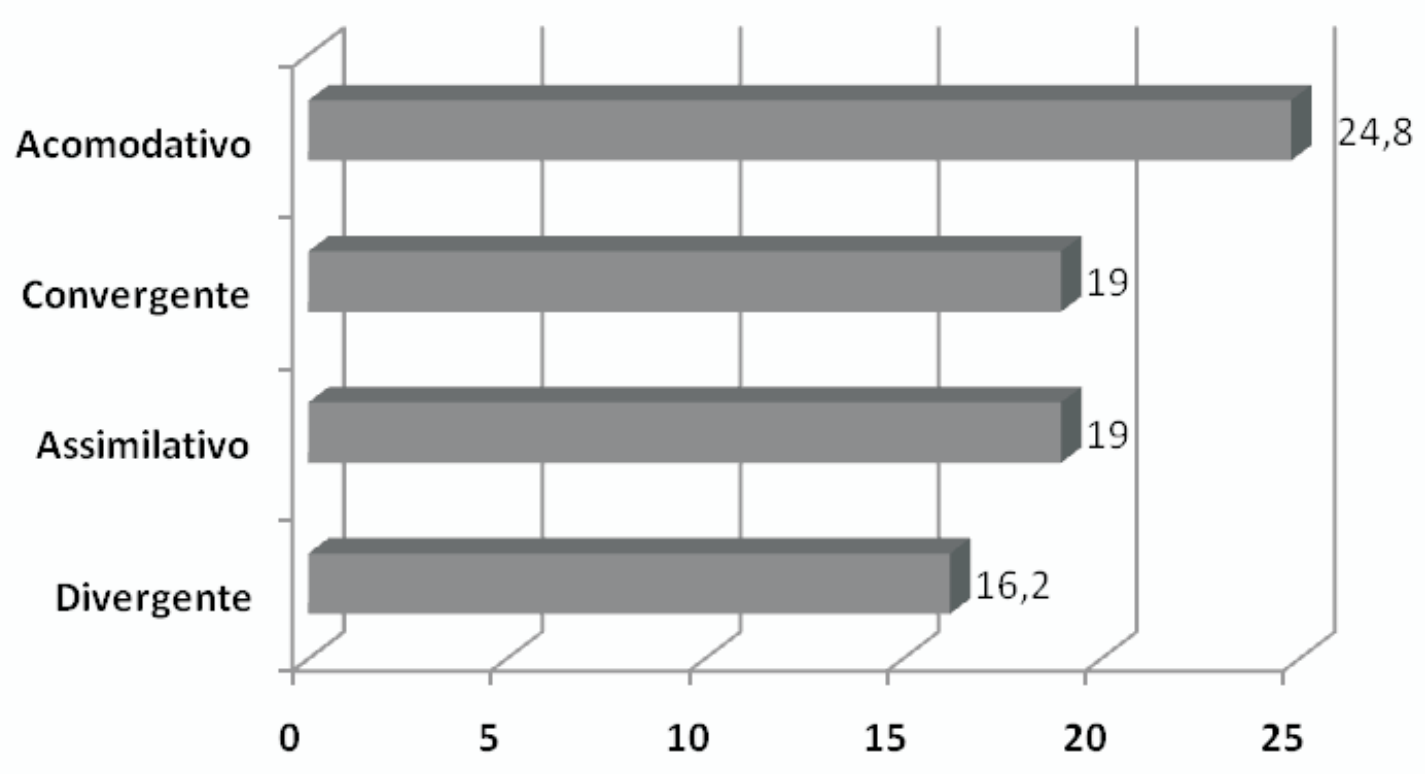
vivenciais

Gráfico 1 - Frequência dos estilos de aprendizagem dos participantes dos treinamentos

Os resultados apresentados pelo gráfico 1 apontam que o estilo de maior frequência foi o estilo acomodador (24,8\%), seguido pelos estilos convergente (19,0\%) e assimilativo $(19,0 \%)$, o estilo com menor frequência foi o divergente $(16,2 \%)$. Os dados indicam que o perfil de aprendizagem com maior frequência é aquele que apresenta boa capacidade de adaptação, tendo a realização, execução e envolvimento em planos e novas experiências como principais forças características.

Assim, o estilo que predominou é um perfil adaptativo, que apresenta boa capacidade de experimentação de novas experiências e execução de atividades (KOLB, 1997). Os aprendizes que utilizam o estilo acomodador aprendem, principalmente, por meio da ação e da sensação e são sujeitos com a habilidade de aprendizagem através de experiências ativas, práticas e funcionam bem em situações ambíguas e incertas. Em situações de aprendizagens formais, estes sujeitos preferem trabalhos em grupo, com metas e tarefas, trabalho de campo ou testar diferentes abordagens para a manutenção de um mesmo projeto (KOLB, 1984).

Este estilo de aprendizagem (acomodador) parece ser um estilo facilmente adaptado ao método de aprendizagem alvo do treinamento vivencial ao ar livre, uma aprendizagem que enfoca a experiência prática do treinamento (Experimentação Ativa - EA) e a vivência de situações diferenciadas (Experiência Concreta - EC).

A relevância dos estudos dos estilos de aprendizagem para a área da gestão de pessoas e recursos humanos se dá devido à identificação das características pessoais dos integrantes da organização. A caracterização dos atributos pessoais facilita no processo de gestão, permitindo a adequação das práticas às especificidades dos profissionais. 
No caso específico dos treinamentos, os estilos de aprendizagem proporcionam uma leitura do ser humano baseada nas características de aprendizagem, enfatizando aspectos que facilitam e dificultam o processo. Dessa forma, Kolb (1984) ressalta a importância de se reconhecer as características para facilitar o desenvolvimento e a aquisição de conhecimento pelo ser humano. A fim de treinar e desenvolver pessoas, os gestores devem levar em consideração os estilos de aprendizagem, com o intuito de proporcionar o tipo de treinamento que se adeque melhor às características dos membros da organização.

Esta afirmação se confirma com os estudos de Grisi e Britto (2004), que apresentam fatores, como o gênero, a idade, a cultura e o grau de escolaridade, como processos influenciadores na aprendizagem, indicando que a forma de aprender das pessoas é diferenciada de acordo com o desenvolvimento, características biológicas, sociais e psicológicas que influenciam no estilo que cada indivíduo prioriza durante as fases do ciclo de desenvolvimento (KOLB, 1984).

\section{Satisfação com o treinamento}

Entende-se, face ao exposto, que os estilos de aprendizagem propostos por Kolb (1984) parecem influenciar no processo de aquisição de conceitos e experiências. Assim, a estratégia escolhida para proporcionar aprendizagem e crescimento é determinante para a eficácia deste processo e o alcance dos objetivos. Uma das formas de se avaliar a eficácia de programas de treinamento e desenvolvimento é a avaliação da satisfação dos participantes (KIRKPATRICK, 1993).

Neste sentido, foi avaliada a satisfação dos participantes de programas de treinamento e desenvolvimento pelo método do treinamento vivencial ao ar livre. A hipótese levantada foi a de que a satisfação com o treinamento vivencial seria alta em função das características próprias da atividade. A tabela 1 apresenta a frequência (percentual) da satisfação dos participantes com o treinamento vivencial em diferentes técnicas vivenciais.

Tabela 1 - Frequência da satisfação dos participantes com os diferentes tipos de treinamento vivencial

\begin{tabular}{lccc}
\hline \multicolumn{2}{c}{ \% SATISFAÇÃO } & \\
\hline & Muito Satisfeito & Satisfeito & Mais ou menos \\
& & & satisfeito \\
Arvorismo & 56,4 & 41,0 & 2,6 \\
Paintball & 25,0 & 66,7 & 8,3 \\
Dinâmicas de grupo & 36,7 & 56,7 & 6,6 \\
\hline
\end{tabular}

A tabela 1 indica a satisfação dos participantes com os treinamentos vivenciais de arvorismo, paintball e dinâmicas de grupo. Os participantes sentiram-se mais satisfeitos nos treinamentos de arvorismo (56,4\% com muita satisfação), seguidos do treinamento de dinâmicas $(36,7 \%)$ e em terceiro lugar o treinamento de paintball $(25,0 \%)$.

A associação entre a satisfação nos diferentes treinamentos evidenciou significância estatística apenas entre os percentuais de satisfação dos treinamentos de arvorismo e dinâmicas, indicando que há uma tendência à satisfação ser maior nos treinamentos que utilizam a 
técnica vivencial do arvorismo em relação ao treinamento que utiliza as técnicas das dinâmicas $(P=0,006)$. Na associação entre os outros treinamentos (arvorismo X paintball; paintball X dinâmicas), não foram observadas significância estatística, indicando que não houve diferença.

Cabe ressaltar que o questionário que avaliou a satisfação dos participantes com o treinamento era composto por uma escala que variava de muito satisfeito para muito insatisfeito. Os dados da tabela 1 evidenciam que o nível de satisfação foi alto para todos os tipos de treinamento, tendo $100 \%$ das respostas para todos os tipos de treinamento variando entre mais ou menos satisfeito $(2,6 \% ; 8,3 \% ; 6,6 \%$; para arvorismo, paintball e dinâmicas de grupo, respectivamente) para muito satisfeito $(56,4 \% ; 25,0 \% ; 36,7 \%$; para arvorismo, paintball e dinâmicas de grupo, respectivamente).

A escolha da satisfação com o treinamento como forma de avaliação da eficácia está baseada nos parâmetros estabelecidos por Kirkpatrick (1993), o qual determina a avaliação da reação direta ao treinamento como um dos índices que determina a eficácia do treinamento. $O$ autor ressalta que esta avaliação é importante porque retrata honestamente a percepção da qualidade do processo por parte dos participantes.

Nesse sentido, a satisfação observada nos participantes dos treinamentos vivenciais ao ar livre pode ser explicada através das características específicas da atividade. O treinamento vivencial é uma atividade que proporciona experiências que podem ser comparadas ao dia a dia das organizações, visando a melhorias e a aprendizagens, entretanto em situações diferenciadas (BOOG, 2006).

O método de aprendizagem focado no treinamento vivencial prediz participação ativa dos integrantes no programa. Pesquisas apontam que o aproveitamento de treinamentos passivos, os quais não requerem a participação, não passa de $5 \%$, podendo alcançar o percentual de 85\% de aproveitamento quando o treinamento possui caráter ativo (MOTOROLA UNIVERSITY, 2002). Dessa forma, o treinamento do tipo vivencial se diferencia por promover a oportunidade de experimentação ativa e vivência das atividades e, assim, dos conteúdos do programa proposto, facilitando a sua absorção.

Especificamente em relação ao treinamento vivencial do arvorismo, a vivência ao ar livre favorece a quebra de paradigmas, superação de limites, enfrentamento de desafios, capacidade de lidar com emoções, vivenciando-as, controlando-as favorecendo a mudança comportamental (ZVINGILA, 2002). Dessa forma, a diferença encontrada na satisfação do arvorismo com o treinamento de dinâmicas de grupo pode ser explicada pelo caráter expositivo e aventureiro do arvorismo, que evoca emoções e enfrentamento de dificuldades na prática e na vivência.

Portanto, a importância do treinamento vivencial e a razão para a satisfação com esta modalidade de treinamento podem ser entendidas pelo fato de o treinamento ir além do aspecto racional e cognitivo, pois o indivíduo experimenta mudanças comportamentais e emocionais que dão a sensação de vitória e autoconfiança. A retenção é maior quando o conteúdo é experimentado, vivenciado e não apenas teorizado (SAUAIA, 1995). Dessa forma, partindo de uma alta satisfação com os treinamentos, optou-se por identificar se houve relação entre o nível de satisfação com o treinamento vivencial ao ar livre para os diferentes estilos de aprendizagem. 


\section{Estilos de aprendizagem X Eficácia do Treinamento ao ar livre}

De acordo com Kolb (1984), o estilo de aprendizagem adotado pelo indivíduo é determinante para um bom aproveitamento do programa ou de determinada atividade/experiência. Estendendo este entendimento ao programa de treinamento vivencial, especificamente os treinamentos vivenciais ao ar livre, objetivou-se identificar se a satisfação com o treinamento vivencial poderia ser influenciado pelos estilos de aprendizagem.

Os resultados obtidos para os estilos de aprendizagem evidenciaram que o estilo de maior predominância foi o acomodador (Gráfico 1), o qual demonstra características de utilizar a criatividade para transferir o conhecimento para o uso próprio, experienciar diferentes situações e executar tarefas e projetos. A predominância deste estilo proporcionou a formulação da hipótese de que os sujeitos do estilo acomodador demonstrariam maior satisfação com o treinamento vivencial por terem como principais características a experimentação ativa e a experiência concreta que se adequam às características do treinamento vivencial ao ar livre.

Os resultados da relação entre os estilos de aprendizagem e o nível de satisfação dos participantes com o treinamento vivencial podem ser observados na tabela 2.

Tabela 2 - Relação entre os estilos de aprendizagem e o nível de satisfação dos participantes com o treinamento vivencial

\begin{tabular}{lccc}
\hline \multicolumn{3}{c}{ \% SATISFAÇÃO } \\
\hline Muito Satisfeito & Satisfeito & Mais ou menos \\
satisfeito \\
Assimilador & 41,1 & 47,1 & 11,8 \\
Convergente & 45,0 & 50,0 & 5,0 \\
Acomodador & 55,0 & 40,0 & 5,0 \\
\hline
\end{tabular}

Os dados da tabela 2 evidenciam que, descritivamente, o estilo de aprendizagem com maior satisfação nos treinamentos vivenciais ao ar livre foi o convergente $(55,0 \%)$, os estilos assimilador e divergente aparecem em sequência (45,0\% e 41,1\%, respectivamente) e no quarto posto o estilo acomodador (30,8\%). Por outro lado, o estilo divergente é o que apresenta maior percentual de participantes menos satisfeitos $(11,8 \%)$ e o estilo acomodador que apresenta maior percentual de satisfação (69,2\%). A associação entre os estilos de aprendizagem e a satisfação com os treinamentos vivenciais não evidenciou relações estatisticamente significativas entre a satisfação e o estilo de aprendizagem $(P=0,05)$.

Os percentuais apresentados pela tabela 2 evidenciam que não há diferenças entre os níveis de satisfação dos participantes dos treinamentos vivenciais ao ar livre, independente do estilo de aprendizagem de cada um. Os dados parecem indicar que o treinamento vivencial ao ar livre tem boa reação (satisfação) e, assim, boa eficácia para qualquer estilo de aprendizagem, obtendo bons parâmetros de avaliação em todos os participantes.

As pesquisas no campo da aprendizagem que utilizaram os estilos de aprendizagem como suporte teórico tem mostrado que os estilos sofrem influência de características específicas, como a personalidade, formação acadêmica, escolha da carreira e ocupação das tarefas que executa no trabalho (KOLB, 1984). Nessa perspectiva, os autores defendem a ideia de que cada atividade tem um estilo de aprendizagem que se adequa de maneira ideal. 
Dessa forma, ao considerar o método do treinamento vivencial ao ar livre, o qual prediz a experimentação ativa e a experiência concreta, levantou-se a hipótese de que os indivíduos com estilo de aprendizagem acomodador apresentariam melhores índices de satisfação do que indivíduos com os estilos divergente, convergente e assimilador. Entretanto, o que foi possível observar é que não houve diferença entre os níveis de satisfação para os quatro estilos de aprendizagem.

Os resultados apresentados na tabela 2 reforçam a ideia de que o treinamento vivencial ao ar livre pode evidenciar boa eficácia a partir do parâmetro da satisfação determinado por Kirkpatrick (1993). A satisfação dos participantes dos programas de treinamento vivencial foi estatisticamente a mesma para todos os estilos de aprendizagem. Esses dados são importantes para o campo da aprendizagem organizacional porque reforçam a relevância do uso de treinamentos vivenciais ao ar livre, os quais parecem demonstrar aceitação pelos participantes com diferentes características pessoais.

Partindo do pressuposto de Milkovich e Boudreau (2000), o qual destaca que treinamento é o processo de desenvolver qualidades nos recursos humanos para habilitá-los a serem mais produtivos e contribuírem melhor para o alcance dos objetivos organizacionais, faz-se importante que gestores e líderes reconheçam que, para um programa de treinamento e desenvolvimento ser satisfatório, deve-se levar em consideração as necessidades estratégicas da organização e também as características individuais de seus membros.

Tendo em vista que a aprendizagem experiencial (KOLB, 1997) é considerada como a capacidade de geração de conceitos a partir da experimentação, a qual é vivenciada e percebida de maneira diferenciada a partir das características do indivíduo e na forma como este recebe e processa as informações, a literatura aponta que programas de aprendizagem devem ser organizados de forma personalizada, a fim de facilitar o acesso e o aproveitamento dos participantes. Este conhecimento é de vital importância para as organizações e seus líderes quando do planejamento de programas de treinamento e desenvolvimento. Entretanto, no caso específico dos treinamentos vivenciais ao ar livre, os resultados do estudo apontam que esta metodologia de ensino é aceita por indivíduos de todos os estilos, tendo altos índices de satisfação. Dessa forma, entende-se que a metodologia dos treinamentos vivenciais, especificamente ao ar livre, engloba características que favorecem a aprendizagem para todas as habilidades da aprendizagem existencial, tanto a experimentação ativa, quanto a experiência concreta, a conceituação abstrata e a observação reflexiva.

Nesse sentido, o método vivencial de treinamento sugere atividades em que os participantes sejam retirados de seus ambientais habituais de trabalho e estimulados a encarar desafios, vencer seus limites e transpor os problemas enfrentados, caracterizando atividades que atraem e satisfazem a todos os estilos de aprendizagem.

Finalizando, a hipótese de que os estilos de aprendizagem poderiam influenciar na eficácia (satisfação) dos treinamentos vivenciais foi refutada, ocorrendo o processo inverso. Os treinamentos vivenciais se apresentaram como atividades com características que instigam a satisfação de indivíduos de todos os estilos de aprendizagem, evidenciando satisfação em todos os estilos e indicando que a prática de treinamentos vivenciais parece ser adequada para quaisquer tipos de estilo individual. 


\section{Conclusão}

A nova conjuntura do mercado de trabalho exige cada vez mais profissionais capacitados e polivalentes, que busquem maior produtividade e diminuição de custos a fim de tornar as empresas mais competitivas. Deste modo, o treinamento pode ser uma importante ferramenta para reciclar conhecimentos e desenvolver habilidades para lidar com os novos processos e sistemas, bem como com as relações humanas nas empresas.

Várias metodologias de treinamento vêm sendo utilizadas, entre elas a vivencial, que tem alcançado destaque por se configurar como um modelo eficaz e dinâmico que proporciona aos participantes a oportunidade de treinar suas estratégias e decisões em situações práticas.

Neste sentido, este estudo objetivou investigar a relação entre os estilos de aprendizagem e o treinamento vivencial ao ar livre, explorando a satisfação dos participantes de programas de treinamento vivencial de uma empresa da cidade de Londrina, Paraná. Com relação aos estilos de aprendizagem, observou-se que o estilo que predominou foi o estilo acomodador, indicando que as características com maior frequência foi de boa capacidade de tomada de decisão, realização de projetos e planos, envolvimento em atividades variadas e novas, bom relacionamento interpessoal e características de liderança.

A resposta dos participantes aos programas de treinamento foi de alta satisfação, tendo 100\% de respostas em índices de satisfação. Foi possível observar uma tendência para melhor satisfação nos treinamentos de arvorismo em relação aos treinamentos de dinâmicas de grupos e paintball. Essa tendência pode ser explicada através das características da atividade, que engloba aspectos físicos, sociais, ambientes e psicológicos.

A análise da relação entre os estilos de aprendizagem e a satisfação com o treinamento vivencial evidenciou que todos os membros, indiferente do estilo de aprendizagem adotado, demonstraram grande satisfação com o treinamento. Constatou-se que, apesar da referência na literatura, a importância do diagnóstico dos estilos de aprendizagem para o planejamento e estruturação de programas de treinamento, os programas de treinamento vivencial parecem adequar-se a todos os estilos, evidenciando características nas atividades que favorecem satisfação para todas as habilidades de aprendizagem.

Neste sentido, os treinamentos vivenciais se apresentam como práticas de características que parecem proporcionar melhor capacidade de aprendizagem e desenvolvimento para populações mistas, com características diferenciadas de aprendizagem. Além disso, a metodologia vivencial ao ar livre permite aos participantes a execução completa do ciclo de aprendizagem proposto por David Kolb; talvez seja esse o motivo pelo qual os participantes deste método demonstrem um índice de satisfação tão alto. Ao final do treinamento, os indivíduos têm a sensação de realmente terem aprendido algo.

\section{Sugestões e recomendações}

Pesquisas subsequentes poderiam avaliar as inter-relações entre os estilos de aprendizagem e a eficácia dos outros modelos de treinamento, dado que, neste trabalho, enfocou-se somente o treinamento vivencial e seria uma importante contribuição ter mais estudos que priorizassem o estilo de aprendizagem de cada indivíduo frente aos diversos treinamentos existentes no mercado. 
É de extrema relevância que se desenvolvam pesquisas no campo organizacional, principalmente com o enfoque no indivíduo, já que, no atual contexto, o maior diferencial das organizações está nos colaboradores que ali trabalham. Deste modo, o fator humano é o mais relevante fator para o progresso da organização e, por isso, é importante o investimento em treinamentos contínuos, dinâmicos, que facilitem a aprendizagem de novos comportamentos e que contribuam para a satisfação dos colaboradores.

Recomenda-se que os gestores e líderes de organizações levem em consideração as características pessoais dos seus colaboradores, a fim de proporcionar-lhes o melhor programa de treinamento e desenvolvimento. Por fim, recomenda-se que o treinamento vivencial seja analisado como uma estratégia eficaz para o treinamento de populações mistas, com diferentes características pessoais.

\section{Referências}

ABTD. Associação Brasileira de Treinamento e Desenvolvimento. Pesquisa: o retrato do treinamento no Brasil 2006/2007. Disponível em: <http:// www.abtd.com.br/material.asp $>$. Acesso em: 10 jan. 2009.

BOHLANDER, G.; SNELL, S.; SHERMAN, A. Tradução Maria Lúcia Rosa. Treinamento e desenvolvimento. In: Administração de recursos humanos. São Paulo: Thomson, 2003. p.133-173.

BOOG, G.G. Manual de treinamento e desenvolvimento: gestão e estratégias/coordenação Gustavo G. Boog, Magdalena T. Boog - São Paulo: Pearson Prentice Hall, 2006b. p. 31-34.

CAMPOS, K.C. de L. et al. Avaliação do sistema de treinamento e desenvolvimento em empresas paulistas de médio e grande porte. Psicologia: Reflexão e Crítica, v. 17, n. 3, p.435-446, 2004.

CASTRO, A. Treinamento é vital para a performance competitiva. Revista T \& D, n. 20, p.6-17, 1998.

GRISI, C.C. de H.; BRITTO, R.P.. Estilos de aprendizagem e o aprendizado em comerciais de tv: em estudo exploratório com o método Kolb. Facef Pesquisa, v.7, n. 1, 2004.

KIRKPATRICK, D.L. Evaluating training programs evidence vs. proof. Training and Development Journal, v. 31, n. 11, p. 9-12, 1977.

. Groupware goes boom, Fortune, v. 128, p. 99-106, 1993.
KOLB, D.A. Psicologia organizacional: uma abordagem vivencial. São Paulo: Atlas, 1978.

Experiential learning: experience as the source of learning and development. New Jersey: Prentice-Hall, 1984.

. A gestão e o processo de aprendizagem. In: STARKEY, K. (Org.). Como as organizações aprendem: relatos do sucesso das grandes empresas. São Paulo: Futura, 1997. p. 321-341.

MILKOVICH, G.T.; BOUDREAU, J.W. Administração de recursos humanos. Tradução Reynaldo C. Marcondes. São Paulo: Atlas, 2000.

MOTOROLA. Motorola University, 2002. Disponível em: <http://mu.motorola.com/>. Acesso em: 16 jan. 2009.

SAUAIA, A.C.A. Satisfação e aprendizagem em jogos de empresas: contribuições para a educação gerencial. 1995. Tese (Doutorado em Administração)-Universidade de São Paulo, São Paulo, 1995.

THOMAS,J.R.; NELSON, J.K. Métodos de pesquisa em atividade física. 3. ed. Porto Alegre: Artmed, 2002.

ULRICH, D. Recursos humanos estratégicos: novas perspectivas para os profissionais de RH. Tradução Bazán Tecnologia e Ligüística. São Paulo: Futura, 2000. 379 p.

VERGARA, S. C. Métodos de pesquisa em administração. São Paulo: Atlas, 2005.

ZVINGILA, E. Manual de gestão de pessoas e equipes. Outdoor Training, 2002. 